\title{
Rarity, proximity, and design actions: mapping strong earthquakes in Italy
}

\author{
Pasquale Cito and Iunio Iervolino*
}

Dipartimento di Strutture per l’Ingegneria e l’Architettura, Università degli Studi di Napoli Federico II, Italy

Article history: received June 23, 2020; accepted October 8, 2020

\begin{abstract}
At the state-of-the-art of structural codes, seismic design actions are based on probabilistic seismic hazard analysis (PSHA). In the performance-based earthquake engineering framework, the return period of exceedance of the reference ground motion is established based on the desired performance of the structure. It is easy to show and recognize that exceedance of elastic spectra, for the most common return periods considered for design, is very likely for some earthquakes if they occur close to the site of interest, and that this does not necessarily contradict the results of PSHA. Therefore, it might be relevant to gather insights about: (i) the probability that the site is in proximity of earthquakes of magnitude that can imply exceedance; (ii) the probability that earthquakes occurring close cause exceedance of design actions; (iii) the minimum magnitude of close-by events that are likely to cause exceedance of design actions, which are then referred to as the strong earthquakes; (iv) the accelerations that structures could be exposed to in the case of exceedance of design spectra. These results, which are produced for Italy in this study, may be considered by-products of PSHA, and are helpful in determining what to expect in terms of elastic actions for code-conforming structures in countries where probabilistic seismic hazard lies at the basis of structural design.
\end{abstract}

Keywords: Performance-based seismic design, seismic hazard, structural safety, bulding code, exceedance of design seismic actions.

\section{Introduction}

The performance-based design framework relies on probabilistic seismic hazard analysis [PSHA; e.g., Mc Guire, 2004], which provides the ground motion intensity at the considered site for a certain exceedance probability in a given time interval. In fact, in the case design seismic actions derive from PSHA, they are typically in the form of response spectra whose ordinates have, individually, the same exceedance return period $\left(T_{r}\right)$; i.e., uniform hazard spectra (UHS). The return period depends on the limit state, that is, the performance of interest, together with design life and intended use of the structure. For example, according to the Italian building code [CS.LL.PP., 2018], ordinary structures designed for the life-safety limit state should withstand seismic actions stemming from the UHS with $T_{r}=475$ years.

It has been shown [Iervolino et al., 2019b] that the exceedance of UHS-based seismic actions is well expected in the epicentral area of earthquakes with moderate-to-high magnitude, especially when PSHA is based on seismic source zones. As a consequence, structures in proximity of earthquakes with magnitude even relatively far from the 


\section{Pasquale Cito and Iunio Iervolino}

maximum considered in the hazard assessment, may be subjected to seismic actions larger than those considered for design. In Iervolino et al. [2019a] it was discussed that the amount of exceedance, that is, the peak-over-threshold or POT, is expected to be non-negligible in the mid- and high-hazard regions. Moreover, Cito and Iervolino [2020] have discussed that the POT can have an effect on seismic structural reliability.

The work presented herein intends to further deepen these issues, providing insights on different questions related to the exceedance of the design spectrum, using the Italy as a case-study and considering two spectral ordinates of the code-prescribed UHS with exceedance return period equal to 475 years, that is, peak ground acceleration (PGA) and 1s spectral pseudo-acceleration (5\% damped). Considering the same source model used to develop the official seismic hazard of Italy, different maps are compiled reporting: (1) the probability that an earthquake with magnitude in a certain interval occurs close to the site, which allows to quantify the chance that a structure in given site in Italy faces earthquakes during its lifetime; (2) the probability that a close-by earthquake causes exceedance of the design actions, which may be useful in understanding which earthquakes pose a threat to code-conforming structures in their epicentral area; (3) the minimum magnitude that, if occurring close to the site, has a probability larger than 0.5 of exceeding selected ordinates of the design (elastic) spectrum, that is, the map of earthquakes which may be defined as strong because, for these scenarios, exceedance is more likely than nonexceedance; (4) the expected value, the $5^{\text {th }}$ and $95^{\text {th }}$ percentile of the acceleration in case of exceedance of the considered UHS, which provide a quantification of the range of seismic action a code-conforming structure can see in the case of exceedance of the design spectrum. All the maps were obtained by discretizing the whole national territory by means of a regular grid consisting of about ten thousand inland sites. These results, which may be considered as by-products of PSHA used to determine design seismic actions, can be of help in understanding in which situations the design safety margins for structures against violation of the limit state of interest are not granted by the elastic design spectrum.

The remainder of the paper is structured such that the basics of PSHA are given first, then the seismic source and attenuation models used in this study are declared. Subsequently, the probability of any site being in proximity of an earthquake with magnitude in a certain interval is mapped, followed by the probability that a close-by earthquake causes exceedance of the design actions. The minimum magnitude of earthquakes, which are expected to cause exceedance of design actions, if occurring close to the site, and the range of acceleration that structures may be exposed to in the case of events exceeding the design actions, complete the results. Some final remarks are also given at the end.

\section{Probabilistic seismic hazard analysis for Italy}

In this section, the basics of PSHA are recalled, subsequently the models to compute the hazard for Italy are listed and discussed. The framing equation of single-site PSHA is equation (1); for a spectral pseudo-acceleration $(S a)$, referring to a given damping factor and natural vibration period $(T)$, it provides the (annual) rate of earthquakes exceeding an arbitrary threshold $(s a), \lambda_{S a(T)>s a}(s a)$ :

$$
\lambda_{S a(T)>s a}(s a)=\sum_{i=1}^{s} v_{i, M \geq m_{\min }} \cdot \int_{r_{\min }}^{r_{\text {max }}} \int_{m_{\min }}^{m_{\max }} P[S a(T)>s a \mid M=m, R=r]_{i} \cdot f_{i, M, R}(m, r) \cdot d m \cdot d r .
$$

In the equation $v_{i, M \geq m_{\min }}, i=\{1,2, \ldots, s\}$, is the rate of earthquakes above the minimum magnitude $\left(m_{\text {min }}\right)$ of interest for each of the $s$ seismic sources affecting the site. The term $f_{i, M, R}(m, r)$ is the joint probability density function (PDF) of magnitude $(M)$ and source-to-site distance $(R)$ for the i-th source. Under the hypothesis that $M$ and $R$ are stochastically independent random variables, it is $f_{i, M, R}(m, r)=f_{i, M}(m) \cdot f_{i, R}(r)$, where $f_{i, M}(m)$ and $f_{i, R}(r)$ are the marginal PDFs of $M$ and $R$, respectively. $f_{i, M}(m)$ is defined between $m_{\min }$ and $m_{\max }$, where the latter is the 
maximum possible magnitude ${ }^{1}$, while $f_{i, R}(r)$ is defined between the minimum $\left(r_{\min }\right)$ and the maximum $\left(r_{\max }\right)$ source-to-site distance, and depends on the position of the site with respect to the source and geometry of the source itself. $f_{i, R}(r)$ is typically computed assuming a uniform distribution of earthquake locations over the source. Finally, $P[S a(T)>s a \mid M=m, R=r]_{i}$ is the conditional probability that an earthquake, with $M=m$ and $R=r$, causes exceedance of the $s a$ threshold at the site of interest. This probability is classically provided by a ground motion prediction equation (GMPE). Usually, GMPEs also include other parameters such as soil type and rupture mechanism that are assumed known, thus, are not treated as random variables. The GMPE also depends on $i$ in the sense that it is usually depending on the prevailing tectonic regime of the source.

Computing equation (1) for different $s a$ values in a range of interest gives the hazard curve for the site, that is the curve providing the exceedance rate of $S a(T)$ as a function of $s a$. To consider different natural vibration periods, and keeping the same damping factor, allows to develop hazard curves for a set of spectral ordinates. Recalling that, under the classical hypotheses of PSHA, the relationship between $\lambda_{S a(T)>s a}$ and $T_{r}$ is such that $T_{r}=\lambda_{S a(T)>s a}{ }^{-1}$ [Cornell, 1968], entering the hazard curves with an exceedance rate equal to the reciprocal of the return period of interest and plotting the corresponding accelerations, say $s a_{T_{r}}$, versus the natural periods, provides the spectrum whose ordinates, taken individually, are exceeded, on average, once every $T_{r}$ years; i.e., the UHS.

\subsection{Source model and hazard map}

All results presented hereafter were obtained considering the source model of Meletti et al. [2008], which features thirty-six seismic source zones, numbered from 901 to 936 (shown in the left panel of Figure 1). Such a model is at the basis of the seismic hazard assessment for Italy described in Stucchi et al. [2011], which provides the UHS for the definition of the structural seismic actions according to the code enforced in the country. The cited study of Stucchi et al. [2011] features a logic tree. In the study herein presented, the branch named 921 was used, as it produces the results claimed to be the closest to those of the full logic tree. For each zone, seismicity is defined in terms of annual rates of earthquakes associated to surface-wave magnitude bins as shown in Table 1 [e.g., Iervolino et al., 2018]. All the bins have width equal to 0.3. The bin which identifies the earthquakes with the lowest magnitude is centered at 4.3 for all sources, with the exception of zone 936 (Etna's volcanic area), for which the central value of the lowest magnitude bin is 3.7, while the largest magnitude depends on the source and is never larger than 7.45. The maximum magnitude for each zone is the largest of the rightmost bin for which the rate is not zero.
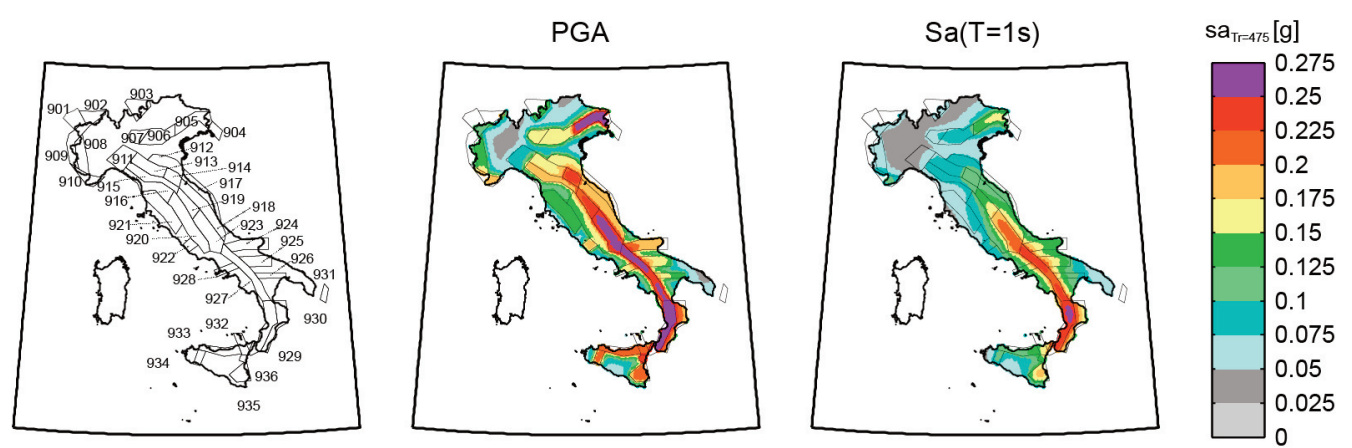

Figure 1. From left to right: Italian seismic source model, hazard map in terms of PGA and $S a(T=1 \mathrm{~s})$ spectral pseudoacceleration with exceedance return period equal to $475 \mathrm{yr}$.

1 These bounds generally depend on the seismic source; however, one can set the largest magnitude interval and consider it for all sources, posing the $\mathrm{i}$-th source's magnitude PDF equal to zero where needed. The same applies to the distance limits. 


\begin{tabular}{|c|c|c|c|c|c|c|c|c|c|c|c|c|c|}
\hline & $\begin{array}{c}3.55- \\
3.85\end{array}$ & $\begin{array}{c}3.85- \\
4.15\end{array}$ & $\begin{array}{c}4.15- \\
4.45\end{array}$ & $\begin{array}{c}4.45- \\
4.75\end{array}$ & $\begin{array}{c}4.75- \\
5.05\end{array}$ & $\begin{array}{c}5.05- \\
5.35\end{array}$ & $\begin{array}{c}5.35- \\
5.65\end{array}$ & $\begin{array}{c}5.65- \\
5.95\end{array}$ & $\begin{array}{c}5.95- \\
6.25\end{array}$ & $\begin{array}{c}6.25- \\
6.55\end{array}$ & $\begin{array}{c}6.55- \\
6.85\end{array}$ & $\begin{array}{c}6.85- \\
7.15\end{array}$ & $\begin{array}{c}7.15 \\
-7.45\end{array}$ \\
\hline 901 & 0 & 0 & 0.0153 & 0.0076 & 0.0166 & 0.0033 & 0.0021 & 0.0021 & 0 & 0 & 0 & 0 & 0 \\
\hline 902 & 0 & 0 & 0.0534 & 0.0153 & 0.0166 & 0.0099 & 0 & 0.0064 & 0.0014 & 0 & 0 & 0 & 0 \\
\hline 903 & 0 & 0 & 0.0992 & 0.0076 & 0.0099 & 0 & 0 & 0.0021 & 0 & 0 & 0 & 0 & 0 \\
\hline 904 & 0 & 0 & 0.0305 & 0.0153 & 0 & 0 & 0.0042 & 0 & 0 & 0 & 0 & 0 & 0 \\
\hline 905 & 0 & 0 & 0.1687 & 0.0904 & 0.0254 & 0.0106 & 0.0085 & 0.0071 & 0 & 0.0033 & 0.0022 & 0 & 0 \\
\hline 906 & 0 & 0 & 0.0663 & 0.0482 & 0.0127 & 0.0021 & 0.0042 & 0 & 0 & 0.0011 & 0 & 0 & 0 \\
\hline 907 & 0 & 0 & 0.0302 & 0.0301 & 0.0021 & 0 & 0.0021 & 0.0014 & 0 & 0 & 0 & 0 & 0 \\
\hline 908 & 0 & 0 & 0.1069 & 0.0076 & 0.0166 & 0.0066 & 0.0021 & 0 & 0 & 0 & 0 & 0 & 0 \\
\hline 909 & 0 & 0 & 0.0305 & 0.0076 & 0.0099 & 0.0066 & 0.0021 & 0 & 0 & 0 & 0 & 0 & 0 \\
\hline 910 & 0 & 0 & 0.0611 & 0.0076 & 0 & 0.0066 & 0.0021 & 0.0064 & 0 & 0.0014 & 0 & 0 & 0 \\
\hline 911 & 0 & 0 & 0.0305 & 0.0076 & 0.0099 & 0 & 0.0021 & 0 & 0 & 0 & 0 & 0 & 0 \\
\hline 912 & 0 & 0 & 0.0482 & 0.0120 & 0.0106 & 0.0148 & 0.0021 & 0.0028 & 0.0012 & 0 & 0 & 0 & 0 \\
\hline 913 & 0 & 0 & 0.1145 & 0.0602 & 0.0169 & 0.0042 & 0.0085 & 0.0014 & 0 & 0 & 0 & 0 & 0 \\
\hline 914 & 0 & 0 & 0.0843 & 0.0663 & 0.0148 & 0.0085 & 0.002 & 0.0057 & 0.0014 & 0 & 0 & 0 & 0 \\
\hline 915 & 0 & 0 & 0.1832 & 0.0763 & 0.0398 & 0 & 0.0042 & 0.0042 & 0.0014 & 0.0014 & 0 & 0 & 0 \\
\hline 916 & 0 & 0 & 0.0458 & 0.0305 & 0.0085 & 0.0042 & 0.0021 & 0 & 0 & 0 & 0 & 0 & 0 \\
\hline 917 & 0 & 0 & 0.0542 & 0.0301 & 0.0114 & 0.0085 & 0.0106 & 0.0064 & 0.0012 & 0 & 0 & 0 & 0 \\
\hline 918 & 0 & 0 & 0.1527 & 0.0229 & 0.0170 & 0.0057 & 0.0085 & 0.0064 & 0.0042 & 0.0014 & 0 & 0 & 0 \\
\hline 919 & 0 & 0 & 0.1298 & 0.0534 & 0.0297 & 0.0106 & 0.0042 & 0.0071 & 0.0043 & 0.0025 & 0 & 0 & 0 \\
\hline 920 & 0 & 0 & 0.1832 & 0.0687 & 0.0568 & 0.0085 & 0 & 0 & 0 & 0 & 0 & 0 & 0 \\
\hline 921 & 0 & 0 & 0.1756 & 0.0840 & 0.0254 & 0.0085 & 0.0021 & 0.0028 & 0 & 0 & 0 & 0 & 0 \\
\hline 922 & 0 & 0 & 0.0458 & 0.0229 & 0.0169 & 0.0042 & 0 & 0 & 0 & 0 & 0 & 0 & 0 \\
\hline 923 & 0 & 0 & 0.4122 & 0.0992 & 0.0767 & 0.0227 & 0.0085 & 0.0106 & 0.0021 & 0.0057 & 0.0043 & 0.0014 & 0.0014 \\
\hline 924 & 0 & 0 & 0.0687 & 0.0382 & 0.0372 & 0.0279 & 0.0140 & 0 & 0.0042 & 0 & 0.0017 & 0 & 0 \\
\hline 925 & 0 & 0 & 0.0458 & 0.0153 & 0.0047 & 0 & 0 & 0 & 0 & 0.0033 & 0.0017 & 0 & 0 \\
\hline 926 & 0 & 0 & 0.0305 & 0.0076 & 0.0186 & 0 & 0.0047 & 0 & 0 & 0 & 0 & 0 & 0 \\
\hline 927 & 0 & 0 & 0.2150 & 0.0561 & 0.0512 & 0.0093 & 0.0047 & 0.0064 & 0.0021 & 0.0042 & 0.0066 & 0.0066 & 0 \\
\hline 928 & 0 & 0 & 0.0154 & 0.0153 & 0.0186 & 0 & 0.0042 & 0.0021 & 0 & 0 & 0 & 0 & 0 \\
\hline 929 & 0 & 0 & 0.2243 & 0.0374 & 0.0651 & 0.0186 & 0.0140 & 0.0140 & 0.0085 & 0.0021 & 0.0017 & 0.0066 & 0.0017 \\
\hline 930 & 0 & 0 & 0.1028 & 0.0093 & 0.0047 & 0.0093 & 0.0093 & 0.0047 & 0.0021 & 0.0021 & 0.0017 & 0 & 0 \\
\hline 931 & 0 & 0 & 0.0193 & 0.0192 & 0 & 0 & 0.0047 & 0 & 0 & 0 & 0 & 0.0021 & 0 \\
\hline 932 & 0 & 0 & 0.0748 & 0.0187 & 0.0166 & 0.0033 & 0 & 0 & 0.0042 & 0 & 0 & 0 & 0 \\
\hline 933 & 0 & 0 & 0.1145 & 0.0153 & 0.0132 & 0.0199 & 0.0066 & 0.0021 & 0.0021 & 0 & 0 & 0 & 0 \\
\hline 934 & 0 & 0 & 0.0280 & 0.0001 & 0.0099 & 0.0033 & 0 & 0 & 0.0021 & 0 & 0 & 0 & 0 \\
\hline 935 & 0 & 0 & 0.0534 & 0.0001 & 0.0166 & 0.0099 & 0.0042 & 0 & 0.0021 & 0 & 0.0023 & 0 & 0.0012 \\
\hline 936 & 0.3359 & 0.0458 & 0.0382 & 0.0153 & 0.0132 & 0.0033 & 0 & 0 & 0 & 0 & 0 & 0 & 0 \\
\hline
\end{tabular}

Table 1. Annual rates for magnitude bins in branch 921 of the hazard model used for design in Italy. 
Using these rates to compute the hazard means to compute the distribution of magnitude as:

$$
\int_{m}^{m+\Delta m} f_{i, M}(u) \cdot d u=\frac{v_{i, M=m}}{v_{i, M \geq m_{\min }}}
$$

where $v_{i, M=m}$ is the rate, for $\mathrm{i}$-th source, of the bin centered at magnitude $m, \Delta m$ is the bin width, and $v_{i, M \geq m_{\min }}$ is the same of equation (1); i.e., it is given by $v_{i, M \geq m_{\min }}=\sum_{m_{\min }}^{m_{\max }} v_{i, M=m}$.

Branch 921 considers the GMPE of Ambraseys et al. [1996] and, for this reason, this model was also used in the present study. According to the GMPE, only earthquakes with magnitude between 4.0 and 7.5 and Joyner \& Boore distance [Joyner and Boore, 1981] up to $200 \mathrm{~km}$ were considered in the analyses. Assuming a uniform epicenter distribution over each seismic source zone, the epicentral distance was converted into the Joyner \& Boore distance according to Montaldo et al. [2005]. The predominant style-of-faulting of each seismic source according to Meletti et al. [2008] was also accounted for in the GMPE by applying the correction factors proposed by Bommer et al. [2003].

These models were also used to compute the reference design seismic actions needed for the elaboration of the maps presented in the next sections ${ }^{2}$. In particular, the design threshold at each site is the spectral pseudo-acceleration, in terms of $S a(T=0 \mathrm{~s})$, that is PGA, and $S a(T=1 \mathrm{~s})$, for which the annual rate of exceedance is $\lambda_{S a(T)>s a}=0.0021$ according to equation (1), that is the ordinates of the UHS with $T_{r}=1 / 0.0021=475$ years; therefore, the corresponding accelerations will be referred to as $s a_{T_{r}=475}$. The values of $s a_{T_{r}=475}$ at any site were derived via the REASSESS software [Chioccarelli et al., 2019] and are presented in the hazard maps of Figure 1 for PGA (center) and $S a(T=1$ s) (right). They were obtained considering rock soil conditions. It is shown that the most hazardous sites are in the central and southern Italy, along the Appenines mountain chain and Calabrian Arc, and in north-eastern area. In particular, the largest accelerations, with exceedance return period equal to 475 years, are below $0.3 \mathrm{~g}$ for both PGA and $S a(T=1 \mathrm{~s})$, and pertain to the areas within zone 905, 923, 927 and 929, whereas the lowest $s a_{T_{r}=475}$ values are found outside seismic sources (in fact, the considered source model does not contemplate any background seismicity) ${ }^{3}$.

It is worth to underline that all results presented in the following, which are based on the maps shown in this section, strongly depend on the seismic source model used for the hazard assessment.

\section{Probability of an earthquake occurring close}

Before introducing the issues related to the exceedance of the seismic actions of the UHS considered by structural design, it could be useful to assess how much the construction site can be affected by an earthquake occurring close during a time interval of interest. This can be translated in quantifying the probability that at least one close-by earthquake, above a given magnitude, occurs in a given time interval $(\Delta t)$. The calculation of this probability starts from the rate of earthquakes above a certain magnitude, $m^{*}$, for the i-th seismic source zone affecting the site, $v_{i, M \geq m^{*}}$, which can be computed as:

$$
v_{i, M \geq m^{*}}=\sum_{m^{*}}^{m_{\max }} v_{i, M=m} .
$$

From this rate it is possible to compute the rate of earthquakes with $M \geq m^{*}$ occurring on the i-th source and within a certain epicentral distance $(w)$ from the site. This rate, denoted as $v_{i, M \geq m^{*} \cap R \leq w}$, can be computed as:

$$
v_{i, M \geq m^{*} \cap R \leq w}=v_{i, M \geq m^{*}} \cdot \frac{A_{i, R \leq w}}{A_{i}},
$$

\footnotetext{
2 The design actions computed herein can be locally different from those of the Italian building code, which are based on the full logic tree. Nevertheless, branch 921 is considered representative enough for the conclusions to be general.

3 The model developers warn that $\mathrm{M} \geq 5$ earthquakes can virtually occur anywhere outside the sources; however, no rate is provided.
} 


\section{Pasquale Cito and Iunio Iervolino}

where $A_{i}$ and $A_{i, R \leq w}$ denote the area of the i-th source and its portion within $w$ kilometers from the site, respectively. At this point, indicating as $N_{M \geq m^{*} R R \leq w}(\Delta t)$ the random variable counting the number of earthquakes above the given magnitude and within the considered distance, in $\Delta t$ years, the sought probability can be computed as:

$$
P\left[N_{M \geq m^{*} \cap R \leq w}(\Delta t) \geq 1\right]=1-e^{-\Delta t \cdot \sum_{i=1}^{s} v_{i, M} \geq_{m}{ }^{*} \cap R \leq w} .
$$

The maps in Figure 2 show, for any site in Italy, the probability that an earthquake with magnitude larger than a certain value (declared in the upper-right corner of each panel) occurs within $5 \mathrm{~km}$ from the site in a time interval $\Delta t=50$ years. It is to note that all maps present white colored areas; sites within them cannot experience any earthquake, according to the considered source model, above the considered magnitude and within $5 \mathrm{~km}$.

The probability of an earthquake occurring close tends to be larger at sites within zones with large maximum magnitude, with some exceptions. Indeed, in order to understand the pattern of the maps, it is worth highlighting that the probability that a close-by earthquake hits the site strongly depends on the $v_{i, M \geq m^{*}} / A_{i}$ ratio in equation (4), which denotes, for the i-th source, the mean annual number of earthquakes with $M \geq m^{*}$ per unit of area of the source. As a consequence, if two sources have comparable rate of earthquakes but different areas, a site in the source for which the rate per unit of area is the largest (i.e., the source with the smallest area) will more likely experience an earthquake within $5 \mathrm{~km}$ in $\Delta t$, according to equation (5).
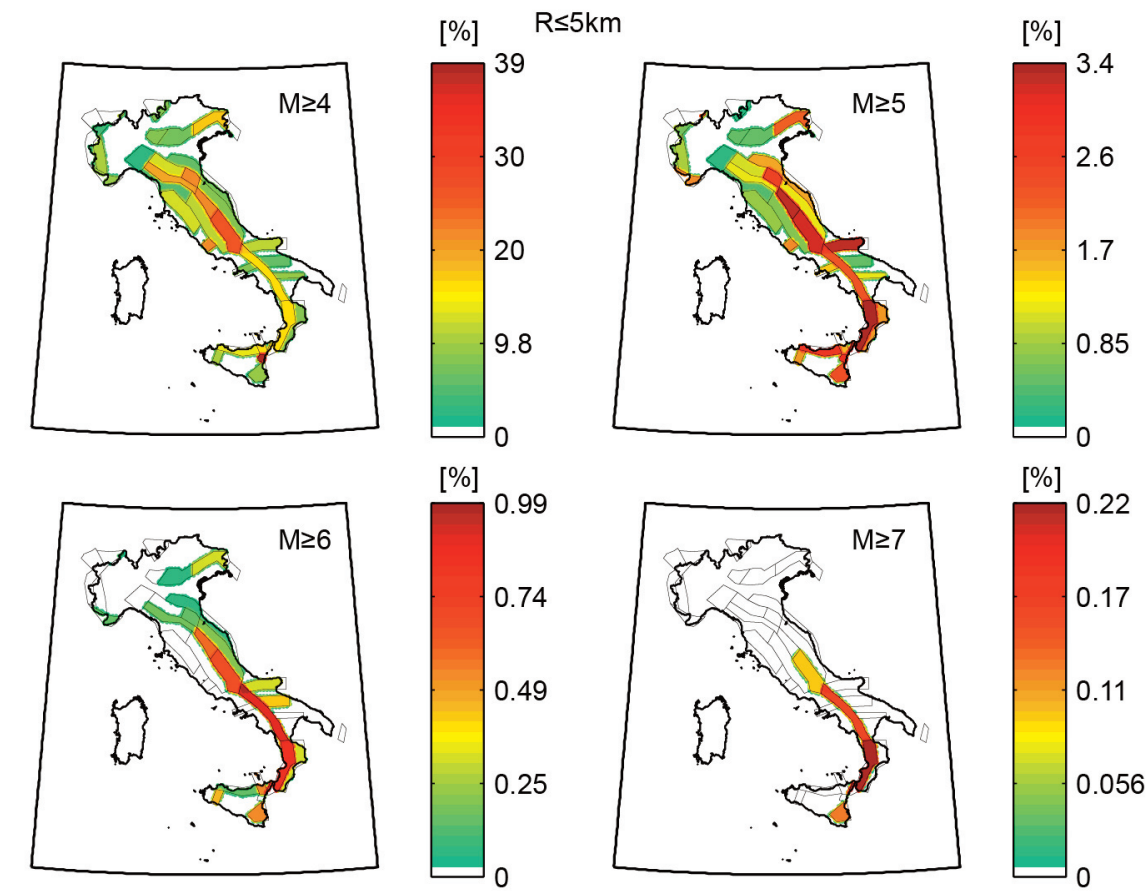

Figure 2. Maps of the probability of an earthquake occurring within $5 \mathrm{~km}$ from the site, in fifty years, considering different magnitude ranges.

To give an example, considering $M \geq 4$, one can note that the largest $P\left[N_{M \geq 4 \cap R \leq 5 \mathrm{~km}}(\Delta t) \geq 1\right]$ value is about $40 \%$ and occurs at sites enclosed by zone 936, which has the central value of maximum magnitude bin equal to 5.2 (i.e., the maximum magnitude for the source is 5.35), whereas most of the sites in zone 923 and 927, for which the maximum magnitude considered in the hazard assessment is 7.45 , have $P\left[N_{M \geq 4 \cap R \leq 5 \mathrm{~km}}(\Delta t) \geq 1\right]$ values between $15 \%$ and $25 \%$. In fact, the rate of earthquakes with $M \geq 4$ per unit of area of the source is equal to $0.012,0.007$ and 0.004 for zone 936, 923 and 927, respectively. 
Increasing the magnitude, it is shown that the probability of an earthquake occurring close decreases at any site, which is well-expected by the decreasing trend of rates in Table 1. However, how much the rate is reduced with respect to $M \geq 4$ depends on the magnitude distribution between 4 and $m^{*}$, which is different for each source ${ }^{4}$. This implies that the pattern of the remaining maps presents some differences with respect to $M \geq 4$. For example, with reference to $M \geq 5$, the largest $P\left[N_{M \geq 5 \cap R \leq 5 k m}(\Delta t) \geq 1\right]$, which is about $3.4 \%$, occurs at sites in zone 929 , for which maximum magnitude is 7.45 . Moreover, for those sites in zone 936 for which $P\left[N_{M \geq 4 \cap R \leq 5 \mathrm{~km}}(\Delta t) \geq 1\right] \approx 40 \%$, the probability of experiencing an earthquake with $M \geq 5$ is now smaller than that observed for most of the sites within zone 923 .

Another interesting result is that large white areas inside seismic sources arise for $M \geq 6$. These areas include sites that cannot experience a close-by earthquake with $M \geq 6$, according to the model, as they are within seismic sources for which the maximum magnitude deemed possible is smaller than 6; e.g., zone 936. The largest probability across the country is about $1 \%$ and, unlike $M \geq 4$ and $M \geq 5$, these values occur at sites within zone 927 . The white colored areas are clearly larger in the $M \geq 7$ map, which reveals that sites that can experience this kind of earthquakes - within $5 \mathrm{~km}$ - are only those in, or very close to, those source zones for which maximum magnitude is larger than 7; i.e., zones 923, 927, 929 and 935. The figure also shows that sites with the largest probability (about $0.2 \%$ ) of being in proximity of a $M \geq 7$ earthquake are found in zone 929 (Calabrian Arc), for which, in fact, the rate of $M \geq 7$ earthquakes per unit of area is the largest.

At this point, it may be useful to extend the discussion introducing the probability of an earthquake occurring over a larger area around the site. To this aim, the maps in Figure 3 and Figure 4 show, for any site, the probability that at least one earthquake occurs within $15 \mathrm{~km}$ and $50 \mathrm{~km}$ in fifty years, respectively. It can be observed that, given magnitude, the probability increases when the distance from the site is increased because, as expected, $v_{i, M \geq m * n R \leq w}$ increases as well. In fact, the larger the $w$-value the wider the portion of the source affecting the site; moreover, when considering large areas around the site, more sources can possibly contribute to the rate.
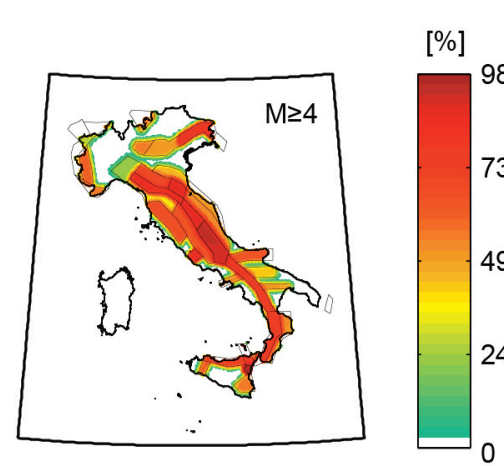

[\%]

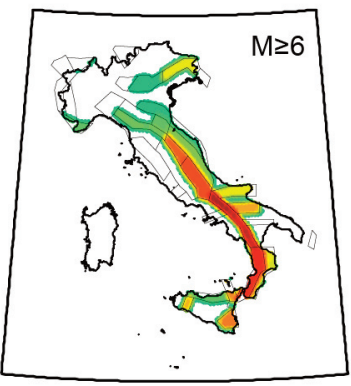

$\mathrm{R} \leq 15 \mathrm{~km}$

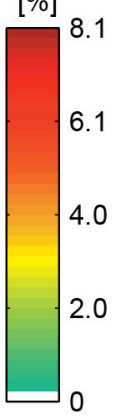

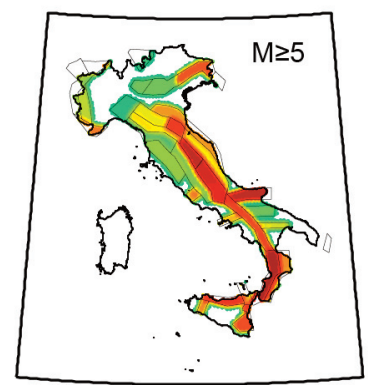

[\%]

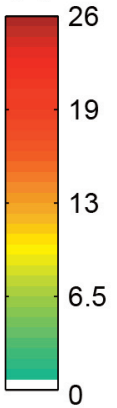

[\%]
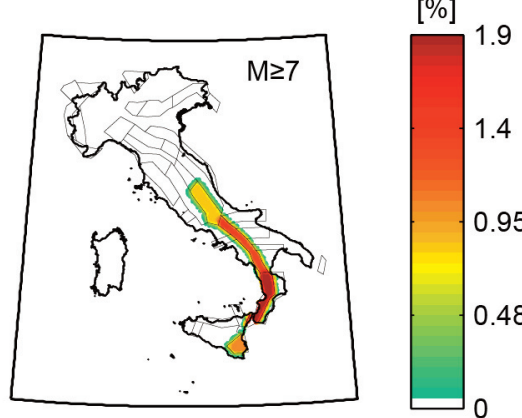

Figure 3. Maps of the probability of an earthquake occurring within $15 \mathrm{~km}$ from the site, in fifty years, considering different magnitude ranges.

\footnotetext{
${ }^{4}$ Calculations were carried out discretizing magnitude by 0.05 step.
} 


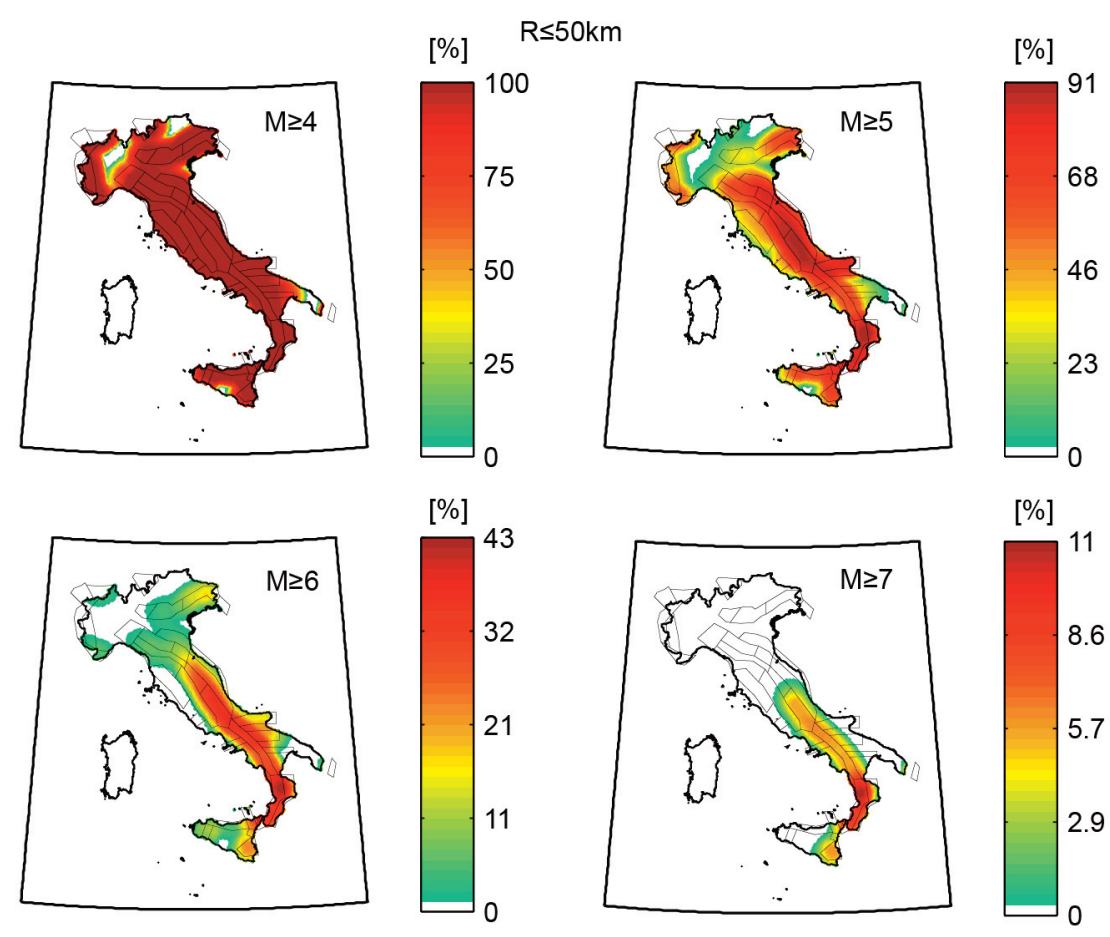

Figure 4. Maps of the probability of an earthquake occurring within $50 \mathrm{~km}$ from the site, in fifty years, considering different magnitude ranges.

Considering $R \leq 15 \mathrm{~km}$, it is shown that the probability can be as high as $98 \%$ for $M \geq 4$ and $2 \%$ for $M \geq 7$. When $R \leq 50 \mathrm{~km}$, large areas in which $P\left[N_{M \geq 4 n R \leq 50 \mathrm{~km}}(\Delta t) \geq 1\right] \approx 100 \%$ are found, that is, most of the sites will be very likely found within $50 \mathrm{~km}$ from an earthquake with magnitude larger or equal than 4 in fifty years. Still with reference to $M \geq 4$, large probabilities can be also found for sites outside the seismic source zones. In fact, due to the high $w$-value, they may be affected by earthquakes by distant sources. At the same time, there are still (small) white areas, meaning that some sites cannot experience any $M \geq 4$ earthquake according to the source model, even considering the occurrence within $50 \mathrm{~km}$.

Looking at the map for $M \geq 6$, it is noted that white areas inside seismic sources reduce with respect to the counterpart in Figure 2 and Figure 3. In other words, some of the sites within sources for which the maximum magnitude is smaller than 6 have non-zero probability of a $M \geq 6$ earthquake occurring within $50 \mathrm{~km}$. This is not surprising, because these sites may also experience an earthquake from other sources for which the maximum magnitude is larger than 6. Finally, the map for $M \geq 7$ reveals that sites along the Appenines mountain chain and the Calabrian Arc, which are the most hazardous regions of Italy (see Section 2.1), have non-negligible probability of experiencing a strong earthquake in fifty years, being between $6 \%$ and $11 \%$.

\section{Probability of exceeding the design actions for earthquakes occurring close}

At this point the second result of the study can be introduced, that is the probability that a close-by earthquake, with magnitude between the minimum and the maximum deemed possible for the site according to the source model, causes the exceedance of the design seismic actions, in terms of selected spectral accelerations (i.e., the two considered ordinates of the UHS) for which it is $T_{r}=475$ years. This result represents an additional information with respect to the previous section, as it provides the probability that $s a_{T_{r}}=475$ is exceeded, once the construction site experienced an earthquake within $w$ kilometers. The sought probability, herein denoted as $P\left[S a(T)>s a_{T_{r}=475} \mid R \leq w\right]$, can be computed as per equation (6): 


$$
\begin{aligned}
& P\left[S a(T)>s a_{T_{r}=475} \mid R \leq w\right]=\sum_{i=1}^{s} \frac{v_{i, M \geq m_{\min }} \cap R \leq w}{v_{M \geq m_{\min }} \Lambda R \leq w} \\
& \cdot \int_{r_{\text {min }}}^{r_{\text {max }}} \int_{m_{\text {min }}}^{m_{\max }} P\left[S a(T)>s a_{T_{r}=475} \mid M=m, R=r\right]_{i} \cdot f_{i, M}(m) \cdot f_{i, R \mid R \leq w}(r) \cdot d m \cdot d r .
\end{aligned}
$$

In the equation, $v_{i, M \geq m_{\min } \cap R \leq w}$ is the rate of earthquakes above the minimum magnitude from the i-th source within $w \mathrm{~km}$ from the site, that is computed as per equation (4), while $v_{M \geq m_{\min } \cap R \leq w}=\sum_{i=1}^{s} v_{i, M \geq m_{\min } \cap R \leq w}$. The $f_{i, R \mid R \leq w}(r)$ term represents the distribution of the source-to-site distance for the i-th seismic source conditional to earthquakes occurrence within $w$ kilometers from the site. For each seismic source this distribution can be computed as:

$$
\left\{\begin{array}{ll}
f_{i, R \mid R \leq w}(r)=\frac{f_{i, R}(r)}{\int_{0}^{w} f_{i R}(r) \cdot d r}, & r \in[0, w] \\
0, & r \notin[0, w]
\end{array} .\right.
$$

Figure 5 gives the map of $P\left[S a(T)>s a_{T_{r}=475} \mid R \leq w\right]$ for PGA (left), and $S a(T=1 \mathrm{~s})$ (right), considering the three $w$-values of the previous section. Comparing these maps with the hazard maps in Figure 1, it can be preliminarily observed that the probability of exceeding the threshold of the UHS, for earthquakes occurring close, has an inverse pattern with respect to the hazard map, independently on the distance range from the site and the spectral ordinate. Looking at the maps, it can be also observed that, analogously to what discussed in the previous section, the white colored areas outside seismic sources denote sites where no earthquakes can occur within $w$ kilometers, according to the source model.

Considering the same $w$-value and different spectral ordinates, it is shown that $P\left[S a(T)>s a_{T_{r}=475} \mid R \leq w\right]$ is larger for PGA than $S a(T=1 s)$ and it has to do with the features of GMPEs [Iervolino et al., 2011]. In the less hazardous areas of the country (see Figure 1), $P\left[S a(T)>s a_{T_{r}=475} \mid R \leq 5 \mathrm{~km}\right]$ is even larger than $80 \%$ for PGA, whereas the maximum probability, in the same areas, does not exceed $40 \%$ in the case of $S a(T=1 \mathrm{~s})$. On average, the relative percentage reduction of $P\left[S a(T=1 \mathrm{~s})>s a_{T_{r}=475} \mid R \leq 5 \mathrm{~km}\right]$, with respect to $P\left[P G A>s a_{T_{r}=475} \mid R \leq 5 \mathrm{~km}\right]$, is about $70 \%^{5}$. However, looking at $R \leq 15 \mathrm{~km}$ and $R \leq 50 \mathrm{~km}$, it appears that the differences between the two spectral ordinates tend to decrease. In fact, the average percentage reduction is about $60 \%$ and $35 \%$, respectively. This is because, given magnitude, the conditional probability of exceeding the threshold of the 475 years UHS, that is, $P\left[S a(T)>s a_{T_{r}=475} \mid M=m, R=r\right]$, decreases faster with the distance in the case of PGA.

Furthermore, it has to be considered that large magnitude scenarios have conditional probability of exceeding $s a_{T_{r}=475}$ larger for $S a(T=1 \mathrm{~s})$ than PGA in a wide range of distances. Thus, since the increasing of $w$ implies, for most of the sites, an increase in the maximum magnitude they can experience according to the adopted source model (see next section), it follows that, when considering high $w$-values, there is an increase in the number of distant and large magnitude scenarios for which the conditional probability of exceeding $s a_{T_{r}=475}$ is larger for $S a(T=1 \mathrm{~s})$ than PGA and, therefore, the difference between the spectral ordinates in terms of $P\left[S a(T)>s a_{T_{r}=475} \mid R \leq w\right]$ reduces with respect to the case in which only the occurrence of close-by earthquakes is considered.

Looking at the figure vertically, that is the same spectral ordinate and considering the occurrence of earthquakes within different distance ranges from the site, it is shown that $P\left[S a(T)>s a_{T_{r}=475} \mid R \leq w\right]$ decreases with the increasing value of $w$ at any site. The explanation is in the fact that increasing $w$ implies that equation (6) includes distant earthquake scenarios for which, given magnitude, $P\left[S a(T)>s a_{T_{r}=475} \mid M=m, R=r\right]$ is comparatively lower with respect to those close-by scenarios with the same magnitude, as expected by the GMPE. However, even considering $R \leq 50 \mathrm{~km}$, non-negligible probabilities of exceeding the ordinates of the 475 years UHS are found, being larger than $10 \%$ for PGA and $5 \%$ for $S a(T=1 \mathrm{~s})$.

\footnotetext{
${ }^{5}$ Measured as $100 \cdot\left\{P\left[P G A>s a_{T_{r}=475} \mid R \leq w\right]-P\left[S a(T=1 s)>s a_{T_{r}=475} \mid R \leq w\right]\right\} \cdot\left(P\left[P G A>s a_{T_{r}=475} \mid R \leq w\right]\right)^{-1}$
} 

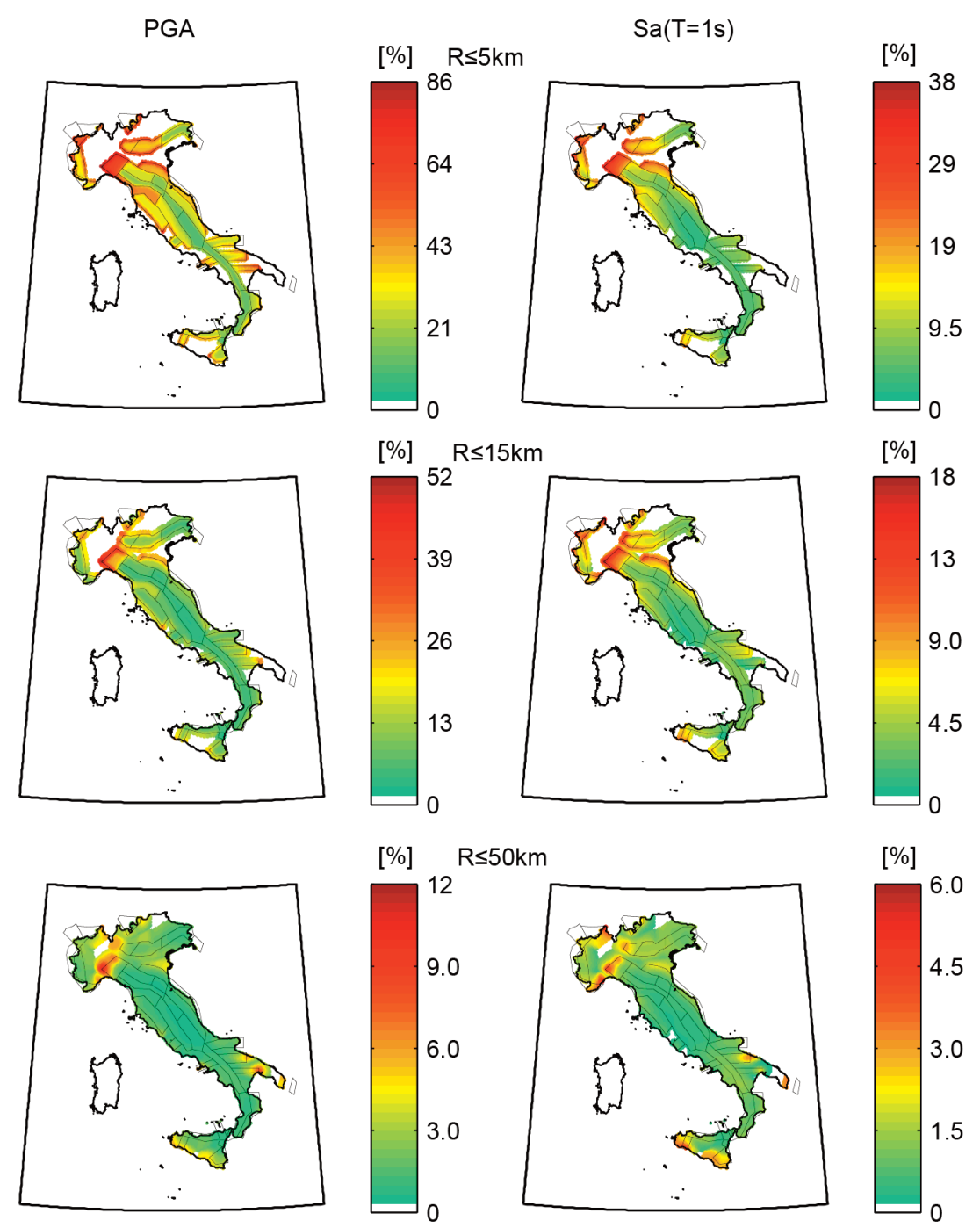

Figure 5. Maps of the probability of exceeding two ordinates of the $475 \mathrm{yr}$ UHS given the occurrence of an earthquake within $5 \mathrm{~km}$ (top), $15 \mathrm{~km}$ (middle) and $50 \mathrm{~km}$ (bottom).

\section{Minimum magnitudes expected to cause exceedance}

The maps in Section 3 showed that sites in the most hazardous areas of the country have non-negligible probability of experiencing a close-by earthquake in fifty years, even considering moderate-to-high magnitude events. Thus, given an earthquake occurring close to the site, one could be interested in knowing the minimum magnitude for which exceedance of the ordinates of the UHS used for design should be expected. For this reason, in this section the concept of strong earthquakes, first introduced in Iervolino et al. [2019b], is addressed. They are intended as the earthquakes that, if occurring close to the construction site, have a conditional probability of exceeding the spectral ordinates of the UHS larger than $50 \%$. In other words, for any site in Italy, this section provides the minimum magnitude for which exceedance of $s a_{T_{r}=475}$ is more likely than non-exceedance, in case of earthquake occurrence within a certain distance from the site. This is helpful in understanding which earthquakes are a threat for code-conforming structures in their epicentral area.

Considering all seismic sources within the $w$ distance from the site, the minimum magnitude causing exceedance of the spectral ordinates of the UHS with $T_{r}=475$ years at any site, denoted as $M_{S a(T)>s a_{T r=475} \mid R \leq w}$, can be computed as: 


$$
M_{S a(T)>s a_{T r=475} \mid R \leq w=\arg _{M} \min }\left\{\sum_{i=1}^{s} \frac{v_{i, M=m} \cap R \leq w}{v_{M=m} \cap R \leq w} \cdot \int_{r_{\min }}^{r_{\text {max }}} P\left[S a(T)>s a_{T_{r}=475} \mid M=m, R=r\right]_{i} \cdot f_{i, R \mid R \leq w}(r) \cdot d r>0.5\right\}
$$

Results are given in Figure 6; in particular, the top, middle and bottom panels show the maps of the minimum magnitude causing exceedance of the threshold of the 475 years UHS in terms of PGA (left) and $S a(T=1 \mathrm{~s})($ right), given the occurrence of an earthquake within $5 \mathrm{~km}, 15 \mathrm{~km}$ and $50 \mathrm{~km}$, respectively. The top panels show that the minimum magnitude for which the conditional probability of exceeding $s a_{T_{r}=475}$, given an earthquake within $5 \mathrm{~km}$ from the site, is larger than 0.5 , tends to be higher in the case of $\operatorname{Sa}(T=1 \mathrm{~s})$. In fact, on average across the country it is $M_{S a(T)>s a_{T_{r}=475} \mid R \leq 5 \mathrm{~km}}=5.7$ for the latter, whereas it is $M_{S a(T)>s a_{T_{r}=475} \mid R \leq 5 \mathrm{~km}}=5.2$ for PGA.

Still with reference to the top panels, it can be observed that for most of the sites the minimum magnitude of strong earthquakes is far from the maximum deemed possible for the sources enclosing them, especially in the most hazardous regions of the country, and this is the main result of this section. For example, for most of zone 923 it is $M_{S a(T)>s a_{T_{r}=475} \mid R \leq 5 \mathrm{~km}}=6.0$ in the case of PGA, and $M_{S a(T)>s a_{T_{r}=475} \mid R \leq 5 \mathrm{~km}}=6.2$ for $S a(T=1 \mathrm{~s})$, while the maximum magnitude for the source is equal to 7.45 according model described above. (This is expected and does not question the result of the hazard analyses; see Iervolino et al. [2019b] for a discussion).

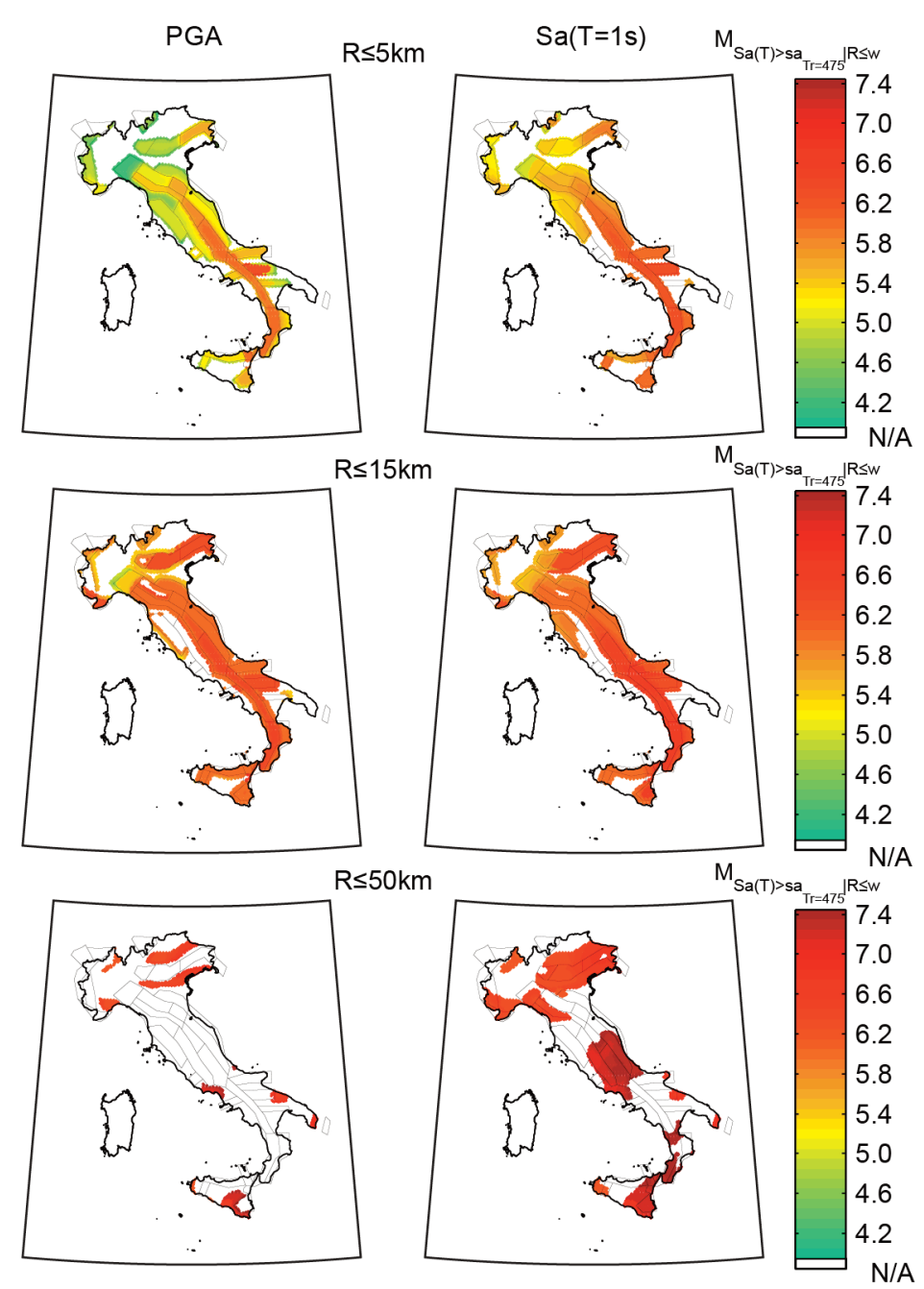

Figure 6. Maps of minimum magnitude with probability larger than 50\% of exceeding two ordinates of the $475 \mathrm{yr}$ UHS, given earthquake occurrence within $5 \mathrm{~km}$ (top), $15 \mathrm{~km}$ (middle) and $50 \mathrm{~km}$ (bottom). 


\section{Pasquale Cito and Iunio Iervolino}

The white areas in the maps denote sites for which earthquakes within $5 \mathrm{~km}$ cannot occur according to the source model, or sites for which the probability of exceeding $s a_{T_{r}}=475$ is smaller than 0.5 even for earthquakes with the maximum magnitude considered possible for the source they are enclosed into.

The panels referring to $15 \mathrm{~km}$ and $50 \mathrm{~km}$ show that, as expected, the minimum magnitude causing exceedance of the ordinates of the UHS increases with the increasing distance from the site. In fact, for both PGA and $S a(T=1 \mathrm{~s})$, the average $M_{S a(T)>s a_{T_{r}=475} \mid R \leq 15 \mathrm{~km}}$ is about 6 for $R \leq 15 \mathrm{~km}$ and about 7 for $R \leq 50 \mathrm{~km}$. This means that, given an earthquake within $50 \mathrm{~km}$, magnitude around 7 is required to have at least $50 \%$ probability of exceeding the considered ordinates of the UHS with $T_{r}=475$ years. On the other hand, Table 1 shows that the maximum magnitude deemed possible is smaller than 6 for some sources and does not exceed 7 in most cases. For this reason, when considering $R \leq 50 \mathrm{~km}$, for most of the sites there is no magnitude, among those considered by the source model, that has probability larger than $50 \%$ of exceeding the considered spectral ordinates: the white areas ${ }^{6}$. These white areas are clearly larger in the case of PGA because it attenuates faster with distance with respect to $S a(T=1 \mathrm{~s})$, according to the GMPE.

Results discussed so far illustrate that the UHS is not hard to be exceeded even for earthquakes with relatively moderate magnitude, if they occur close to the construction site. Conversely, exceedance is not expected for distant earthquakes or those of low magnitude occurring close. To better illustrate this point, it is worthwhile looking at Figure 7. In the top panels, the maps of the maximum magnitude which can occur within each distance range, $M_{\max \mid R \leq w}$, are given (according to the source model described in Section 2.1).

The middle and bottom panels, referring to PGA and $S a(T=1 \mathrm{~s})$, respectively, show for each site the difference between the maximum magnitude possible and the minimum magnitude of strong earthquakes (i.e., those of Figure 6); such a difference is indicated as: $\delta M=M_{\max \mid R \leq w}-M_{S a(T)>s a_{T_{r}=475} \mid R \leq w}$. One can observe that $\delta M$ decreases with the increasing $w$-value and it is larger for PGA than $S a(T=1 \mathrm{~s})$. Considering $R \leq 5 \mathrm{~km}$ (left), the average $\delta M$ over the country is 1.2 and 0.8 for PGA and $S a(T=1 \mathrm{~s})$, respectively. It is also noted that $\delta M$ can be as high as 2.8 , thus confirming that close-by earthquakes with magnitude far from the maximum considered in the hazard assessment are likely to cause the exceedance of the UHS with $T_{r}=475$ years. Looking at $R \leq 15 \mathrm{~km}$ (center), $\delta M$ is, on average, equal to 0.6 for PGA and 0.5 for $S a(T=1 \mathrm{~s})$, even if there are still sites where it is about equal to 1 . Finally, when considering $R \leq 50 \mathrm{~km}$ (right), in the colored (i.e., non-white) areas, the average $\delta M$ is below 0.3 for both spectral ordinates.

\section{Seismic action given exceedance of design spectra}

In the previous section it has been discussed that the exceedance of the UHS considered for design can be more likely than not when the construction site is in proximity of an earthquake with moderate-to-high magnitude. This implies that structures in that areas may be required to withstand seismic actions larger than those considered by design. For this reason, it may be worthwhile to assess what to expect, in terms of spectral acceleration, when the exceedance of the UHS occurs. This was recently introduced by Iervolino et al. [2019a] as the expected peak over threshold. It is the expected value (i.e., the mean) of $S a(T)$ conditional to the exceedance of the design threshold of the UHS; i.e., $E\left[S a(T) \mid S a(T)>s a_{T r=475}\right.$. Indeed, in Cito and Iervolino [2020], it was shown the PDF of $S a(T)$ given the exceedance of $s a_{T_{r}=475}, f_{S a(T) \mid S a(T)>s a_{T_{r}=475}}(s a)$, can be computed as:

$$
f_{S a(T) \mid S a(T)>s a_{T_{r}=475}}(s a) \cdot d(s a)=\frac{\left|d \lambda_{S a(T)>s a}\right|}{\lambda_{S a(T)>s a_{T=475}}}, \forall s a>s a_{T r=475} .
$$

In the equation, $d \lambda_{S a(T)>s a}$ represents the derivative of the hazard curve at the site truncated at the design threshold, while $\lambda_{S a(T)>s a_{T_{r}=475}}=0.0021 \mathrm{yr}^{-1}$.

The maps in Figure 8 and Figure 9 are intended to show the range of variability of the POT, in terms of PGA and $S a(T=1 \mathrm{~s})$, respectively, in the case the exceedance of $s a_{T_{r}=475}$ occurs. In both the figures, the top panels show, from left to right, the $5^{\text {th }}$ percentile $\left(s a_{5 \%}\right)$, the expected value and the $95^{\text {th }}$ percentile $\left(s a_{95 \%}\right)$ of the POT, computed from the distribution in equation (9), evaluated for each site. The middle and bottom panels show the absolute $(\Delta)$

6 White areas outside the seismic sources in the bottom panels also include those sites that cannot experience earthquakes within $50 \mathrm{~km}$. 

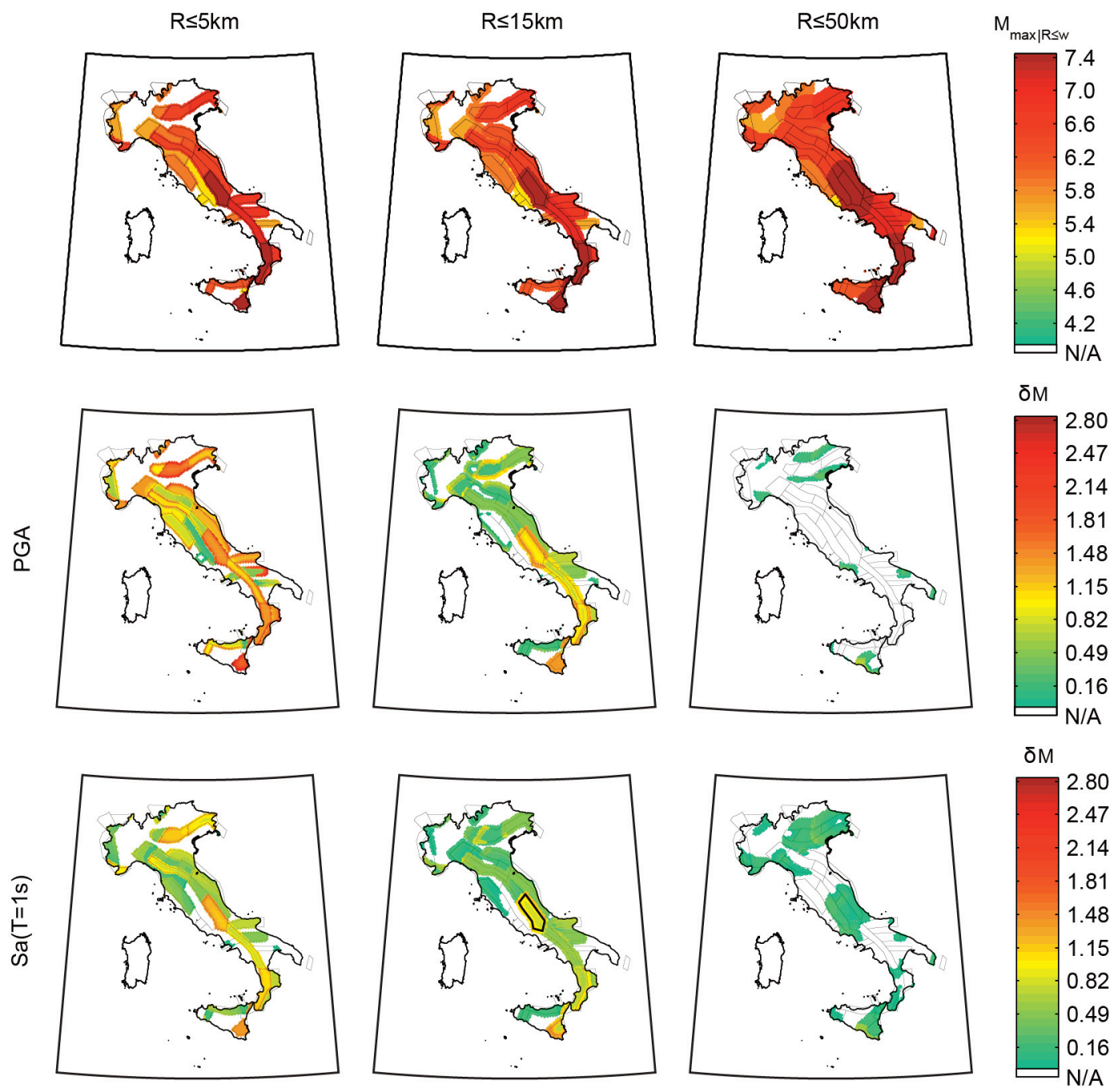

Figure 7. Top: maximum magnitude each site can experience within $5 \mathrm{~km}$ (left), $15 \mathrm{~km}$ (center) and $50 \mathrm{~km}$ (right). Middle and bottom: difference between the maximum and minimum magnitude of strong earthquakes in terms of PGA and $S a(T=1 \mathrm{~s})$, respectively.

and percentage $\left(\Delta^{\%}\right)$ differences with respect to the threshold, respectively. With reference to $s a_{5 \%}$, these differences are defined as $\Delta=s a_{5 \%}-s a_{T r=475}$ and $\Delta^{\%}=100 \cdot \Delta / s a_{T r=475}$. Replacing $s a_{5 \%}$ with $E\left[S a(T) \mid S a(T)>s a_{T_{r}=475}\right]$ and $s a_{95 \%}$ provides $\Delta$ and $\Delta^{\%}$ for the expected POT and $95^{\text {th }}$ POT percentile, respectively. In both figures, the location where the maximum for each map occurs is also provided.

The top panels of the figures show that the $5^{\text {th }}$ and $95^{\text {th }}$ percentile and the expected value of the POT are larger in the most hazardous areas of the country. Looking at the middle and bottom panels, it is shown that the largest excursions over the UHS are expected at the highest vibration period. For both PGA and $S a(T=1 \mathrm{~s})$, the smallest absolute and relative amount of exceedance of $s_{T_{r}=475}$ are found in the low-seismicity regions, that is outside the seismic sources, whereas the largest excursions over the threshold occur in the most hazardous areas.

With reference to the $5^{\text {th }}$ POT percentile, it can be observed that it is close to $s a_{T_{r}=475}$ across all the country, and - in fact - the maximum values of $\Delta$ and $\Delta \%$ are below $0.01 \mathrm{~g}$ and $5 \%$, respectively, for both the considered spectral ordinates. Indeed, $s a_{5 \%}$ represents the spectral acceleration that has $95 \%$ probability of being exceeded given the exceedance of the UHS. In other words, it grossly indicates how low can be the POT. 


\section{Pasquale Cito and Iunio Iervolino}

Considering the expected POT for $S a(T=1 \mathrm{~s})$, it is shown that the maximum excursion over the threshold is $0.25 \mathrm{~g}$ in terms of absolute difference and $153 \%$ in terms of percentage increment. This means that an acceleration about 2.5 times the design threshold is expected if the exceedance of the UHS with $T r=475$ years occurs.

Looking at the maps of $s a_{95 \%}$ in terms of $S a(T=1 \mathrm{~s})$, that is, the maps of the spectral acceleration at each site with $5 \%$ probability of being exceeded, given the exceedance of $S a(T=1 \mathrm{~s})$ with $T_{r}=475$ years, large excursions

$5^{\text {th }}$ percentile
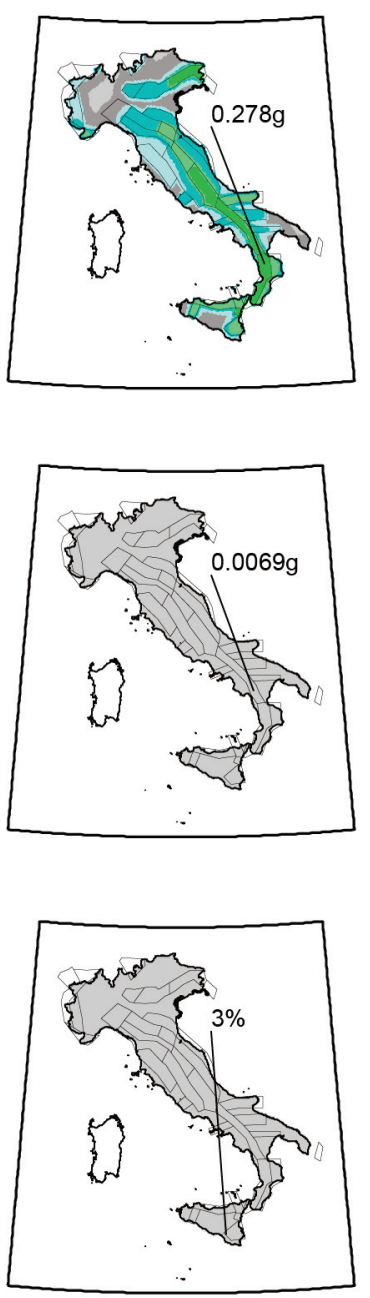

Expected value

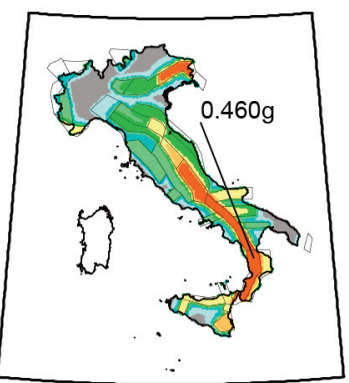

$\therefore$
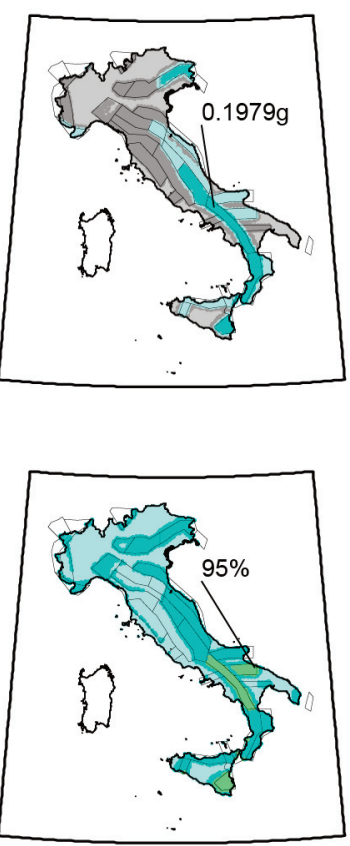

$95^{\text {th }}$ percentile
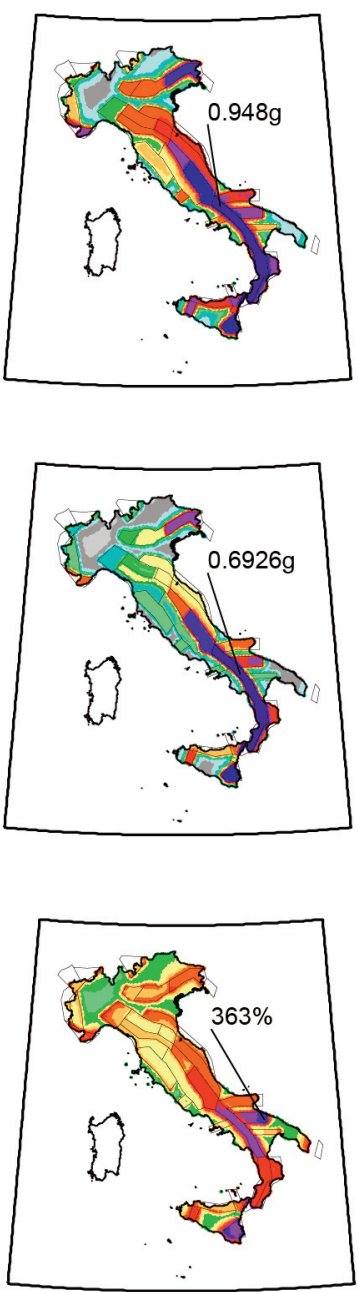

[g]

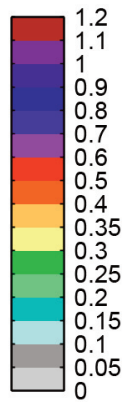

$\Delta[\mathrm{g}]$

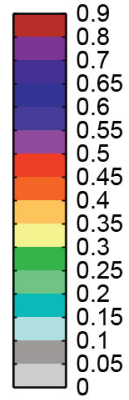

$\triangle^{\%}[\%]$

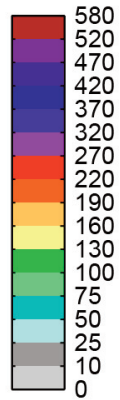

Figure 8. Top: Maps of the $5^{\text {th }}$ percentile, expected value, and $95^{\text {th }}$ percentile of the POT given the exceedance of the PGA threshold with $475 \mathrm{yr}$ return period at each site; middle is the absolute difference with respect to the $475 \mathrm{yr}$ threshold; bottom is the percentage amount of exceedance. 
above the design threshold can be found in the most hazardous area, being the maximum $\Delta$ and $\Delta^{\%}$ equal to $0.9 \mathrm{~g}$ and $580 \%$, respectively. This result reveals that, given the exceedance of the 475 years UHS, structures in the highest hazardous areas of the country may be exposed to elastic seismic actions, in terms of $S a(T=1 \mathrm{~s})$, about seven times those considered for design, according to the considered hazard model ${ }^{7}$.

$5^{\text {th }}$ percentile
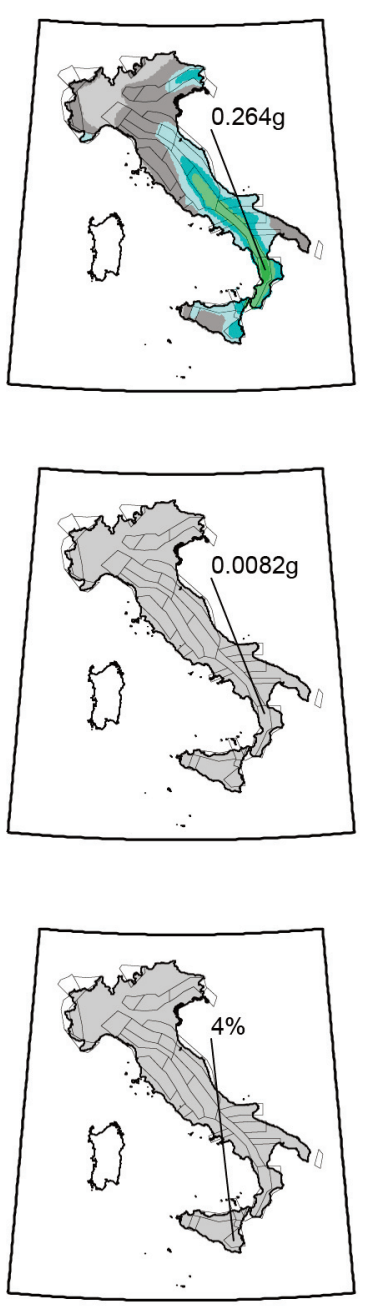

Expected value
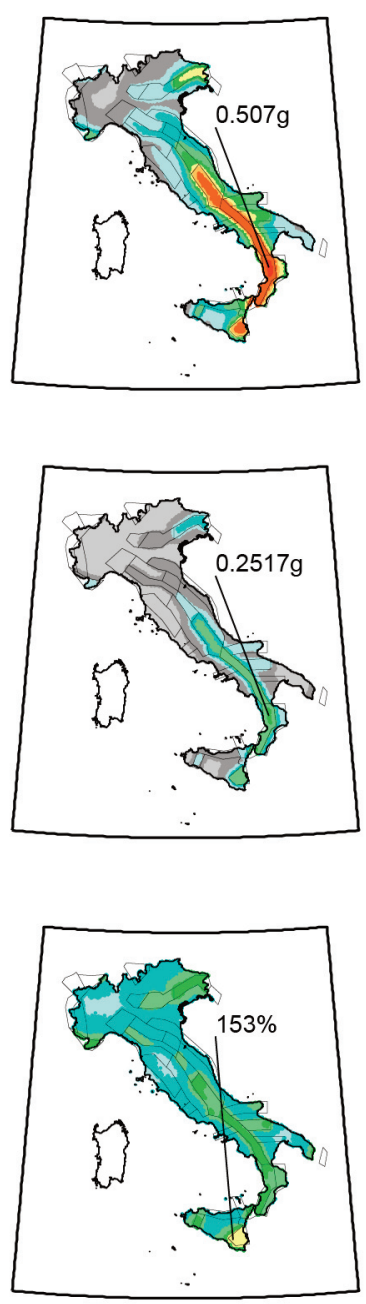

$95^{\text {th }}$ percentile
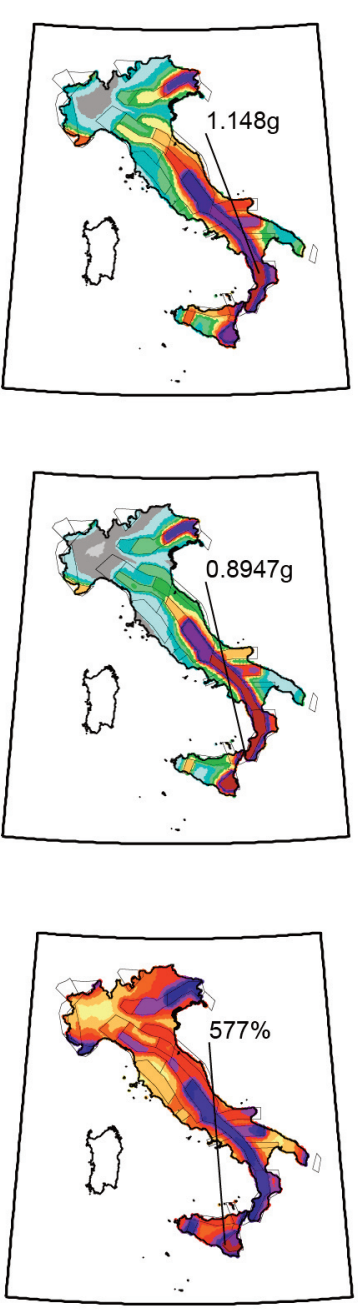

[g]

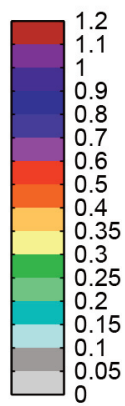

$\Delta$ [g]

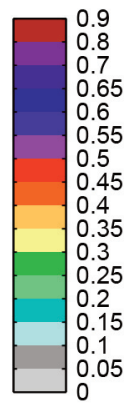

$\Delta^{\%}[\%]$

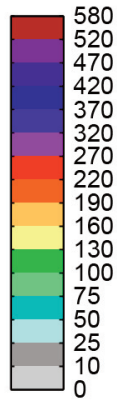

Figure 9. Top: Maps of the $5^{\text {th }}$ percentile, expected value, and $95^{\text {th }}$ percentile of the POT given the exceedance of the $S a(T=1 s)$ threshold with $475 \mathrm{yr}$ return period at each site; middle is the absolute difference with respect to the $475 \mathrm{yr}$ threshold; bottom is the percentage amount of exceedance.

${ }^{7}$ Note however, that this is subjected to the suitability of the considered hazard model to evaluate exceedance rates of large accelerations with return periods possibly much larger than those used for design. 


\section{Pasquale Cito and Iunio Iervolino}

\section{Final remarks}

In the framework of performance-based earthquake engineering, the seismic actions considered for structural design derive from probabilistic seismic hazard analysis via uniform hazard spectra. Often, the design UHS' are likely to be exceeded, in case of earthquakes close to the construction site, even if the event magnitude is far from the maximum considered in the hazard assessment. The consequence of interest to structural engineering is that codeconforming structures found in proximity of these earthquakes may be exposed to seismic actions larger than those accounted for by design, and that this does not necessarily contradicts the results of hazard analysis. With reference to Italy, the simple study presented herein aimed at providing further insights on this issue. The study considered the seismic source model which is at the basis of the definition of the design seismic actions according to the current Italian building code. Furthermore, two spectral ordinates of the UHS with exceedance return period equal to 475 years were considered: PGA and $S a(T=1 \mathrm{~s})$.

The discussion was first focused on the quantification of the probability that an earthquake occurs within a certain distance from the site in fifty years, considering different magnitude intervals. Subsequently, assuming that an earthquake occurs within a certain distance from the site, the probability of observing the exceedance of the considered ordinates of the UHS, and the minimum magnitude for which such an exceedance should be expected, were mapped. These latter events where referred to as strong earthquakes, because exceedance of the UHS is more likely than not when they occur. Finally, in order to explore the range of seismic actions structures may be subjected to in the case the exceedance of the UHS occurs, the maps of the expected value and the $5^{\text {th }}$ and $95^{\text {th }}$ percentile of the acceleration given exceedance of the selected spectral ordinates of the UHS were also given. The following conclusions are worth recalling.

1) Sites enclosed in seismic sources for which the annual rate of earthquakes, per unit of area of the source, is high, have the largest probability of a $M \geq 4$ earthquake occurring within $5 \mathrm{~km}$ in fifty years. The largest probabilities across Italy are larger than $30 \%$ and occur at sites in the Etna's volcanic area. This probability increases with the increasing distance range. When the occurrence of earthquakes within $50 \mathrm{~km}$ is considered, it was found that the majority of sites in Italy very likely will experience a $M \geq 4$ earthquake in fifty years. In the most hazardous regions probabilities as high as $11 \%$ were obtained considering the occurrence of $M \geq 7$ earthquakes within 50 $\mathrm{km}$ from the site.

2) Given the earthquake occurrence within a certain distance from the site, the probability of exceeding the selected spectral ordinates with 475 years return period is the largest where the hazard is the lowest and viceversa. Such a probability decreases with the increasing distance from the site and is larger for PGA than $S a(T$ $=1 \mathrm{~s}$ ). In the less hazardous areas of the country, and considering the occurrence of earthquakes within $5 \mathrm{~km}$ from the site, the probability of exceeding the threshold with 475 years return period can be as high as $86 \%$ and $38 \%$ for PGA and $S a(T=1 \mathrm{~s})$, respectively. In the same areas, non-negligible probabilities were also found in the case of occurrence of earthquakes within $50 \mathrm{~km}$; i.e., about $12 \%$ for PGA and $6 \%$ for $S a(T=1 \mathrm{~s})$.

3) The maps of minimum magnitude of strong earthquakes together with the maps of the maximum magnitude deemed possible for the sites revealed that exceedance of the 475 years UHS should be expected for close-by earthquakes of relatively moderate magnitude. In central Italy, and along the Appenines mountain chain, where the maximum magnitude considered in the hazard assessment is equal to 7.45 , the minimum magnitude of earthquakes that, if occurring within $5 \mathrm{~km}$ from the site, are expected to cause exceedance, is between 6.0 and 6.3 for both PGA and $S a(T=1 \mathrm{~s})$. On average over the country, such a magnitude is larger for $S a(T=1 \mathrm{~s})$ than PGA. When considering larger distance ranges, for most of the sites no scenarios for which exceedance is more likely than non-exceedance can be identified, as the minimum magnitude of strong earthquakes is larger than the maximum magnitude deemed possible for most of the seismic sources.

4) The peak-over-the-threshold distribution strongly varies from site to site. The largest excursions over the spectral ordinates of the UHS are expected at the most hazardous sites. Given the exceedance of the 475 years UHS, the expected and 95 $5^{\text {th }}$ POT percentile can be as high as 2.5 times and almost seven times the design threshold, respectively, while the $5^{\text {th }}$ POT percentile is close the the threshold across Italy. In the less hazardous sites, that is those outside seismic sources, the amount of exceedance is smaller.

All results obtained in this study, which strongly depend on the seismic source model employed for the hazard assessment, can be used to quantitively assess what to expect for code-conforming structures exposed to close-by earthquakes, when the definition of the elastic seismic actions for structural design derives from PSHA. 
Acknowledgements. The study presented in this paper was developed within the activities of ReLUIS (Rete dei Laboratori Universitari di Ingegneria Sismica) for the project ReLUIS-DPC 2019-2021.

\section{References}

Ambraseys, N. N., K. A. Simpson, and J. J. Bommer, 1996, Prediction of horizontal response spectra in Europe, Earthq. Eng. Struct. Dyn., 25, no. 4, 371-400, doi:10.1002/[SICI]1096-9845[199604]25:4<371::AID-EQE550>3.0.CO;2-A.

Bommer, J. J., J. Douglas, and F. O. Strasser, 2003, Style-of-Faulting in Ground-Motion Prediction Equations, Bull. Earthq. Eng., 1, 171-203.

Chioccarelli, E., P. Cito, I. Iervolino, and M. Giorgio, 2019, REASSESS V2.0: software for single- and multi-site probabilistic seismic hazard analysis, Bull. Earthq. Eng., 17, no. 4, 1769-1793, doi:10.1007/s10518-018-00531-X.

Cito, P., and I. Iervolino, 2020, Peak-over-threshold: quantifying ground motion beyond design., Earthq. Eng. Struct. Dyn., 49, no. 5, 458-478.

Cornell, C. A., 1968, Engineering Seismic Risk Analysis, Bull. Seismol. Soc. Am., 58, no. 5, 1583-1606, doi: http://dx.doi.org/10.1016/0167-6105[83]90143-5.

CS.LL.PP., 2018, Decreto Ministeriale: norme tecniche per le costruzioni, Gazzetta Ufficiale della Repubblica Italiana, n. 42, 20 febbraio, Suppl. Ordinario n. 8. Ist. Polig, e Zecca dello Stato S.p.a., Rome.

Iervolino, I., E. Chioccarelli, and V. Convertito, 2011, Engineering design earthquakes from multimodal hazard disaggregation, Soil Dyn. Earthq. Eng., 31, no. 9, 1212-1231, doi:10.1016/j.soildyn.2011.05.001.

Iervolino, I., E. Chioccarelli, and M. Giorgio, 2018, Aftershocks' Effect on Structural Design Actions in Italy, Bull. Seismol. Soc. Am., 108, no. 4, 2209-2220, doi:10.1785/0120170339.

Iervolino, I., M. Giorgio, and P. Cito, 2019a, The peak over the design threshold in strong earthquakes, Bull. Earthq. Eng., 17, no. 3, 1145-1161, doi:10.1007/s10518-018-0503-9.

Iervolino, I., M. Giorgio, and P. Cito, 2019b, Which earthquakes are expected to exceed the design spectra?, Earthq. Spectra, no. In press, 032318EQS066O, doi:10.1193/032318EQS066O.

Joyner, W. B., and D. M. Boore, 1981, Peak horizontal acceleration and velocity from strong-motion records including records from the 1979 Imperial Valley, California, earthquake, Bull. Seismol. Soc. Am., 71, no. 6, 2011-2038.

Meletti, C., F. Galadini, G. Valensise, M. Stucchi, R. Basili, S. Barba, G. Vannucci, and E. Boschi, 2008, A seismic source zone model for the seismic hazard assessment of the Italian territory, Tectonophysics, 450, nos. 1-4, 85-108, doi:10.1016/j.tecto.2008.01.003.

Montaldo, V., E. Faccioli, G. Zonno, A. Akinci, and L. Malagnini, 2005, Treatment of ground-motion predictive relationships for the reference seismic hazard map of Italy, J. Seismol., 9, 295-316.

Robin K. Mc Guire, 2004, Seismic Hazard And Risk Analysis, Earthquake Engineering Research Institute, Oakland, California.

Stucchi, M., C. Meletti, V. Montaldo, H. Crowley, G. M. Calvi, and E. Boschi, 2011, Seismic Hazard Assessment [20032009] for the Italian Building Code, Bull. Seismol. Soc. Am., 101, no. 4, 1885-1911, doi:10.1785/0120100130.

"CORRESPONDING AUTHOR: IUnio IERVOLINO,

Dipartimento di Strutture per l'Ingegneria e l'Architettura,

Università degli Studi di Napoli Federico II,

via Claudio 21, 80125, Naples, Italy.

e-mail: iunio.iervolino@unina.it

(c) 2020 the Istituto Nazionale di Geofisica e Vulcanologia.

All rights reserved 